\title{
Organizational Policies on Personnel Training and Development: The Need to Increase Productivity in the Nigeria's Tertiary Institutions Beyond Covid 19
}

\author{
Mrs. Lawretta, Adaobi Onyekwere, $\mathrm{PhD}$ \\ Department of Sociology, Faculty of Social Sciences, \\ Rivers State University, Nkpolu, Oronworukwo, Port Harcourt \\ ORCID ID: 0000-0001-5640-3907; \\ Mrs. Obuzor Mezewo Emerinwe \\ Department of Sociology, Faculty of Social Sciences, \\ Rivers State University, Nkpolu, Oronworukwo, Port Harcourt \\ ORCID ID: 0000-0001-7836-3977
}

\begin{abstract}
The performance of personnel in an organizational setting such as a university for future roles and responsibilities is dependent upon training and development. Thus, the training and development of personnel has become an invaluable asset in the accomplishment of organizational set goals around the world. It is in this vein that this study examines the need to train and develop personnel with the view to increase their productivity in the Nigeria's tertiary institutions beyond covid 19. The study adopts survey research design and three research questions were formulated to guide the study with the adoption of Exchange theory of Peter Blau as theoretical framework. Data were collected through questionnaires, interviews, and observations. Among the findings, study concurs that training and development of personnel serves is bedrock for high productivity, consolidation and sustainability of organizational goals. In addition, the study reveals that workers through value addition can efficiently perform their jobs, gains spirited improvement and seek self growth. Furthermore, the study reveals that investment in training and development develop employees in their current jobs, prepares them for tomorrow's opportunities and responsibilities and at the same time, transfers information and knowledge into practice with a view to enhancing organization usefulness and productivity. As a result of these findings, the study concludes that adequate manpower development in universities designed with a clear mission and vision, and well-articulated policy, and strategic plan, will improve the performance of personnel in achieving organizational set goals beyond COVID 19 epoch. Based on this, the study recommends that since personnel are highly esteemed resource of organization, employers of labour should be conscious about training and development and the retention of employees. Finally, every organization should have personnel that can adjust swiftly in unpredictable business environments to achieve set goals for the increase of productivity and growth of the economy.
\end{abstract}

Keywords: Training and Development; Retention of personnel; Organizational performance; COVID-19 pandemic

DOI: $10.7176 /$ RHSS/10-16-08

Publication date:August $31^{\text {st }} 2020$

\section{Introduction}

As organizations strive to cope with the consequences of COVID-19 pandemic, finding a sustainable and valuable human resource to regain lost grounds has become very important at the moment than ever. In this day and age, the intensification for competent personnel to propel the growth of organizations beyond the COVID-19 plague has been identified in the training and development of personnel, a process that re-engineers personnel to perform their jobs efficiently, gain competitive advantage and above all, improves organizational productivity. Agreeing to this position, Khawaja \& Nadeem (2013) also maintain that organizations are in the chase for knowledgeable personnel that can adjust swiftly in unpredictable business environments to achieve set goals for the increase of productivity and growth of the economy. By extension, this statement holds that the transfer of information and knowledge to employers of labour through training and development of their personnel enhances organization effectiveness and productivity when that information and knowledge acquired is put into practice in the day-to-day- management of organizations

Since the World Health Organization (WHO) first declared COVID-19 a world health emergency in January 2020, there has been a global public health and economic crisis that has affected the $\$ 90$ trillion global economy beyond anything experienced in nearly a century (James K. Jackson, et al (2020). As a result, organizations have been attempting to address the public health crisis and economic considerations with a view to balancing competing policy objectives and achieving set goals. In this regard, policymakers and financial and 
commodity market participants generally have been hopeful of a global economic recovery starting in the third quarter of 2020, assuming there is not a second wave of infections(James K. Jackson, et al (2020). Sequel to this, organizations are contending that without a quick resolution of the health crisis, the economic crisis may persist longer than most forecasters have assumed. However, with social distancing guidelines and close down businesses that had begun opening as a result of a risein new confirmed cases of COVID-19, emphasis is at the moment being placed on the building of an organizational structure with a clear mission and vision, including a strategic plan to train and develop personnel to increase the level of efficiency in organizations beyond the COVID 19 pandemic.

Since organization's policies and procedures make employees understand the organization's views and values on specific issues, and the consequences if they are not followed, organizations are increasingly recognizing the need to use best training and development practices to clean up their personnel to enhance their spirited benefit to accomplish agreed goals. Writing earlier, Moses (1999) said organizations had begun to invest, and plan for future through implementing policies on training and development of personnel for prospective exalted positions. Concurring, Nda and Fard (2013) submit that the acquisition of knowledge triggers development. In addition, they contend that the success of organizations is reliant on its knowledgeable, skilled as well as experienced workforce. Thus, for organizations to maintain sustainability, they must continue to acknowledge that training and development of personnel as important.

Prior to COVID 19, the International Labour Organization ILO (2006) indicated that organizations in the United States spent a total of $\$ 55.8$ billion on their Training and Development Policies (hereafter TDP). The net direct training expenditure averaged USD458 per employee and 1.3 percent of the total gross wages and salaries. This number had increased substantially with the compounded growth rate being around 5 percent in 2010, since 1996. In another report, Paradise (2007) stated that U S organizations alone spent more than $\$ 126$ billion annually on training and development of personnel. In an environment where high uncertainty tends to present organizations with high risk, the knowledge of academic and productive intelligence present organizations with a reliable competitive advantage over those that do not have such, mostly when training and development is viewed important(Jelena, 2007). Obviously, this is where the country's universities are expected to make optimum contributions to organizational growth and development through the intensification and diversification of their programmes for the development of high level human resources base to increase productivity.

From the foregoing, it is most beneficial for personnel to perform their work in an improved method, but for the realization of this, organizations must make available appropriate tools to accomplish this responsibility. In line with this school of thought, Garger (1999) says with training and development programmes, personnel can become critical philosophers to change organizational outlook and behaviour. Similarly, Nunn (2000) submits that training and development will usher in improvement; however, they have to be attractive to personnel and also seen as a basic requirement to achieve their dreams in organizations. In addition, Kraiger (2003) asserts that successful organizations should invest more in training and development than other organizations since these training and development programmes will lead to improvements in the organizational performance and results(Dolezalek 2005; Salas and Cannon-Bowers 2001).

Nowadays, as organizations are under pressure to achieve their goals in the global economy, as well as trying to make a distinction on the basis of talents, information, and passion for their workforce, higher productivity and job satisfaction are the focus (Khawaja \& Nadeem, 2013). Based on this, it is certain that training and development programmes to enhance both employees and organizations are vital to the expansion of organizations. In this vein, each organization that invests seriously in the area of training and development will obtain the benefits of an enriched working environment with higher levels of staff retention as well as increased productivity and performance.

Concurring, Vinesh (2014) holds that training and development guide is oriented essentially around what is good for people, rather than what is profitable for organizations. The reason for this, he argues, is that in terms of training, and development, what is good for people is good for the organizations in which they work - what is good for people's development is good for organizational performance, quality, customer satisfaction, effective management and control, and therefore profits too. Further, Vinesh posits that organizations which approach training and development of personnel from this stand point inevitably motivates them to excel, and most importantly, makes them stay around for long enough to become great at what they do, and in the end help newly recruited personnel to become invaluable to organizations. Lending credence to the stated, some scholars suggest that training opportunities increase high personnel yield, whereas other scholars like Colarelli and Montei (1996) hold that training is an instrument which is beneficial for employee retention. Judging from these viewpoints, it is an indisputable fact that training and development of personnel is a complicated human resource practices that can expressively direct the understanding of organizations' goals. Underneath this submission, Goldstein and Ford (2002) maintain that training and development is a well thought-out system of learning which expands the efficiency and productivity of individual, group, and organization. While viewing training as basic, it is important to state that development, in this context, refers to activities leading to the acquisition of 
new knowledge or skills for purposes of upward movement in organizations.

From the foregoing, training has become priceless in increasing productivity of organizations. It does not only enhance employees resourcefully, but also provides them with an opportunity to virtually learn their professions and stand out more knowledgeably. Supporting this assertion, Ekaterini and Constantinos-Vasilios (2009) contend that training is one of the most all-encompassing techniques to enhance the efficiency of individuals through which organizational goals are communicated to personnel. Corroborating, Rohan \& Madhumita (2012) also sustain that investing in training of personnel on decision making, teamwork, problemsolving and interpersonal relations has beneficial impact on the organizations' level of growth, as well as impacting on employees' performance. What this seems to admit is training and development will guarantee achieving set goals without compromising competence. Thus, in the present competitive society, institutions are required to know about the philosophy of training and development in order to assist personnel effectively carry out the activities in appropriate manner. That is, justifying one's qualifications through skills and competence when assigned a responsibility.

Prior to the contributions of Anyamele (2004) and other contributors on the import of personnel training and development, scholars like Duke (1992) states that higher education institutions should recognize that their personnel as vital and valued asset, and as such, should train and develop them to ensure that their graduates are well nurtured to compete exceptionally with their peers all over the world. But available literature evidence seems to hold that universities are reluctant to commit themselves to encourage and facilitate their personnel to realize their potentials, gain knowledge, skills, and experience necessary to enhance their contributions to meeting their respective dreams and aspirations, and as well as organizational objectives. Clearly, this development speaks volumes about the essence of organizational policies on personnel training and development and the need to increase productivity beyond COVID-19 era in the country's universities. Accepting the foregoing as accurate, there is no doubt that universities are essential components that can create formidable academic workforce capable of meeting the demands of their vision and mission through training and development of personnel to re-position themselves to achieve desired goals.

Based on this, Nigeria's tertiary institutions needs to be seriously re-evaluated. to train and develop highquality professional performance resulting in career advancement, strategic development, and initiative to sustain change for tomorrow. As a result, the thoughtfulness of training and development of personnel in in the Nigeria's tertiary institutions beyond covid 19

\subsection{Statement of the problem}

From the foregoing analysis, it is obvious thatc organizational policies and procedures are an essential part of any given organization. These are employed to protect the rights of organization employees as well as the interests of employers. Rules of conduct within an entity, outlining the function of both employers and the organization's workers are streamlined to train and develop personnel to attain higher productivity for organizations and work satisfaction for employees. Howver, most organizations, particularly universities do not seem to key into the tenets of training and development of personnel. As a result, the quality of graduates from Nigerian Universities is declining rapidly, and do not seem to meet the demands of employers. Onuoha and Ewuzie (2012) explanation that the often rejection of most graduates of Nigerian universities by employers of labour are located in poor skills acquisition and incompetence in their supposed specialized areas. In other words, personnel to groom these students are deficient in the acquisition of a new direction that will incorporate the most excellent proficient development frameworks to realize the set goal of producing competent graduates. Based on this, Nigeria's tertiary institutions needs to be seriously re-evaluated to train and develop high-quality professional performance resulting in career advancement, strategic development, and initiative to sustain change in the Nigeria's tertiary institutions beyond COVID- 19

It is therefore the objective of this study to analyze and offer understanding on the impacts of organizational policies on personnel training and development and the need to increase productivity in the country's tertiary institutions beyond COVID-19. To this effect, this study has the following specific objectives:

(i) To examine how training and development can help universities increase the competence of their personnel in order to maximize productivity beyond COVID-19.

(ii) To determine how training and development can improve the retention of qualified personnel in the universities to confront unforeseen circumstances beyond COVID-19

(iii) To assess how training and development can be improved through academic and scientific collaborations beyond COVID-19

In the attempt to achieving these objectives, three research questions were also formulated to guide the study. These are:

(a) What is the impact of training and development in improving the competence of personnel in order to maximize productivity beyond COVID-19?

(b) How can training and development of personnel improve their retention beyond COVID-19? 
(c) Can training and development of personnel improve academic and scientific collaborations beyond COVID-19?

Based on the foregoing, this study will motivate other researchers in a wider scale to examine the the impacts of organizational policies on personnel training and development and the need to increase productivity in the country's tertiary institutions beyond COVID-19.

\section{Theoretical framework}

\subsection{Exchange theory}

There are many versions of exchange theory. However, the proponent of the exchange theory employed in this study is that of Peter Blau, born in Austria in 1918; became a US citizen in 1943 and received his PhD in 1952 from Columbia University, has contributed immensely to studies of formal organizations.

Peter Blau's exchange theory tries to build a bridge between the micro (face to face) and macro(interconnected) relationship in larger organizational and societal settings. Blau, in his presentation, explains more complex structural relations using some basic concepts of utilitarianism, cost, rewards, profits, value and others, and is of the view that imbalance is the determinant factor in any exchange. This imbalance occurs when a party in exchange is capable of rewarding the other partner more than the other partner (the recipient) is capable of reciprocating. If one is always at the receiving end in exchange, the giver tends to morally, psychologically, economically, politically and socially build a situation of imbalance and therefore create a super-ordinate-subordinate structure in the relationship. This is where the exchange theory becomes relevant in this study as most organizations have abandoned the policies of training and developing their personnel because they tended to consider the cost implications, and for this reason, they constantly decide the fate of their personnel without considering the negative impact on organizations. In this vein, they become the superior partner or creditor $(+)$, while the employees who coordinate the workings of the organizations are foisted the inferior status. However, the failure to redress this imbalance has seen many organizations, including universities not able to retain their personnel.

Essentially, the exchange theory proposes that constructive work-related performance and attitudes mainly depend on the perception of personnel who believe that their organizations are taking care of them. The emotional agreement between employer and employee are the central element of organizational performance. Corroborating, Gould-Williams (2007) holds that organizations originate social exchange theory when they choose to be concerned with the interest of their personnel, on the other hand, personnel respond with optimistic attitudinal and behavioural replies supportive to their organization (Settoon, Bennett and Liden 1996). Concisely, this social exchange agreement produces a durable psychological bond between employee and organization (Garrow 2004).

\section{Review of Related Literature}

\subsection{Training and development programmes for personnel higher productivity}

Training can be defined as a systematic process of providing employees with certain competencies, such as knowledge, skills and abilities, so that they would be able to carry out their current jobs effectively and efficiently (Lepak and Gowan 2010). On the hand, the term development refers to learning experiences that focus more on the long term, for preparing personnel for responsibilities in different jobs, usually at the management level (Lepak and Gowan 2010). Both training and development performance are important for organizations because it is impossible for them to grow and compete in this current highly competitive and globalised business environment without them. However, training and development is often viewed as a waste of resources, and are implemented just to comply with legal requirements.

As a term, training and development has been variously defined. For Ana Paula Vieira Gomes Ferreira(2016), it is a tool that enhances organizational performance, competitiveness, and economic growth. Substantiating, they submit that state both organizations and employees, as well nations, need training: Workers need it to develop their careers or to get better compensations; organizations need skillful and efficient employees to improve performance and productivity, promote competitiveness, decrease absenteeism and turnover, as well as to improve client satisfaction; governments depend heavily on a skilled labour force with the capacity to learn, adapt, and master competitiveness in a globalized economy. In other words, organizational training and development programmes are basics for the training and development of personnel for the improvement of their skills and abilities. It is a complex process because it is not just a mere training. It rather incorporates different modes of training: in-service training, orientation programs, refresher courses, conference presentation, research work, workshop attendance, and academic interaction, peer learning and even self development. In their inspirational contribution, Satterfield and Hughes (2007) arguably state that training and development affect personnel conduct and their working skills which result into their improved performance as well as constructive changes. Supporting their position, Konings and Vanormelingen (2009), Colombo and Stanca (2008) and Sepulveda (2005) also agree that training is an instrument that fundamentally affects the 
accomplishment of organizations' goals and objectives.

However, it is to be pointed out that the most select purpose of every organization is to generate high revenue and maximize profit and the most fundamental tool to realize this is an efficient and effective workforce. Thus, the training and development of personnel in any organization is only efficient and effective if the appropriate guidance and improvement is provided for such to lead to efficiency.

Essentially, the impact of organizational policies on personnel development of any organization, the surroundings notwithstanding, is measured by the accomplishment of its workforce. This assertion is hinged on the fact that training and development is concerned with organizational activity aimed at bettering the performance of individuals and groups in organizational setting (Vinesh, 2014). Adding flesh to his contribution, Vinesh further affirms that the objective of training and development and its continued learning process, has become rather an over arching trend of socio-economic needs that organizations must embrace as a culture of social responsibility to attain both organizational and employees' goals.

Based on this, the characteristics of every organization that has the interests of its staff at heart in the present day competitive environment recognizes swift adjustment, and continuous change for improved services. Most of the corporations are, therefore, investing a lot of money on the training and development of their personnel in order to remain competitive and successful in the present-day challenging times. Aligning to this point, Nishtha and Amit (2010) hold that training and development is very essential at all employee levels because skills erode and become obsolete over a period of time and therefore, has to be replenished. Therefore the commitment to invest in staff development, obviously, can be explained as emotional accord by which employers are usually assured loyalty for long term dedication, and on the other hand, embarking on providing personnel work safety, opportunities for improvement in vocation, and training opportunities (Feldman 2000).

Concurring, Gerbamn (2000) submits that personnel development programmes include a variety of teaching technique, schedule, and helping learning environment that guarantee personnel improvement of their skills and which, are afterward applied on their jobs. Obviously, since training and development process has become very strategic role that organizations are enthusiastic for their personnel to possess for high performance, and they must be a continuously improvement in the methods of training and development applied previously in contemporary times. Consequent upon this, it has become the responsibility of organizations seeking to compete positively on the world-wide stage to embark on training and development programmes for their personnel in order to advance their skills and abilities. Corroborating, Jehanzeb and Bashir (2013) contend that organization development has variously been defined by scholars to the extent that some hold that it is a planned, top down; organization-wide effort to increase the organizations' effectiveness and health. From whichever perspective, organization development in the thoughts of Jehanzeb and Bashir(2013) is a complex strategy intended to change the beliefs, attitudes, values, and structure of organizations so that they can better adapt to new technologies, markets, and challenges. Since development is a dynamic concept, it is not just about anything done to better organization efficiency, but a particular kind of change process calculated to bring about a particular kind of end result as it involves organizational reflection, system improvements, planning and self analysis for the improvement of personnel.

All over the world different organizations, according to Jehanzeb and Bashir (2013) are providing special programmes for the betterment and skill improvement of their personnel which are based on same logic. Contributing, Mel Kleiman (2000) explains that the essentials parts of a worthy employee training programme are designed on orientation, management skills, and operational skills of employees. What is more, Janet Kottke (1999) illustrates that employee development programmes must be in line with core proficiencies, appropriate structure through which organizations develop their activities at corporate level. The basic function of the premise is to gain knowledge, cooperation, inventive thinking and resolving problem (Kottke 1999). Since these suppositions are the groundwork of any employee development programme, Kottke (1999) conclusively says these ideas assist to develop the strategic goals of business by facilitating learning chances and supporting organizational culture. In other words, the requirements for technical training programme for employees for job satisfaction facilitate to realize the culture and success of organization. Therefore, it is imperative that employees are updated with the present knowledge of the job for future responsibilities

Nowadays, most of the organizations are organizing different programmes for the training and development of their personnel, and Nigeria's organizations cannot be far from the current trend. More often than not organizations motivate their personnel by offering them tuition reimbursement package so that they can improve their know-how of specifics beneficial to organizations. For example, Corporate University, according to Rosenwald (2000), offers this benefit to almost 10 percent of her personnel for advancement. However, only senior management and those personnel at apex level are given tuition reimbursement (Rosenwald 2000).

\subsection{Retention of qualified personnel in organizations through training and development}

Writing on the retention of qualified personnel in organizations through training and development, several scholars argued that the knowledge and skills of an organization's workforce are significantly important to firm 
performance, competitiveness, and innovation (Dukhan et al. 2017; Madarisa et al. 2017). Concurring, Kraiger (2003) states that successful organizations invest more in training and development than other organizations because these training and development programmes bring improvements in the organizational performance and results(Dolezalek 2005; Salas and Cannon-Bowers 2001). Thus, personnel training and development has become an inevitable mechanism to implement the recent higher educational reforms that consider interactive studentcentered teaching and learning approaches as an integral element (Seyoum, 2012). Elucidating further, Seyoum (2012) says it enables staff in universities to keep students up-to-date to the current educational trends and new theories, and refurbishes lecturers' repertoires of knowledge, skills, and attitudes. Essentially, personnel training and development also upgrade the problem solving skills of lecturers, and assist them to strengthen friendship and collaborative works and develop the spirit of team work among their colleagues in order to improve the quality of teaching and learning. For these, Desta (2004); Adugna (2006) and Temesgen (2006) tenaciously hold that personnel training and development is one of the significant means to bringing improvement on institutional organizational culture. From this perspective, we hold that universities are synonymous with organizations, and to ensure efficient personnel in line with achieving set goals in the present day global academic and scientific world, organizations must be conscious about training and to sustaining this valuable human resource to achieve job satisfaction and retention of competent personnel.

From the foregoing, it is obvious that several organizations have revealed that one of the attributes that facilitates the retention of staff is to develop them by offering them opportunities to improve their learning (Logan 2000). Contributing, Rosenwald(2000) agrees there is a strong relationship between staff training and development, and as well as their retention. Earlier, Garger (1999) argued that organizations are beginning to realize that experienced personnel are important assets and retaining them would be of huge challenge. In the same vein, Moses (1999) concurs that organizations are beginning to plan for future through implementing policies on training and developing their new personnel for exalted positions in future. This commitment, obviously, can be explained as emotional accord by which employers are usually assured loyalty for long term dedication, and on the other hand, personnel provided work safety, chances for advancement in career, and training opportunities (Feldman 2000). Sequel to this, high performing organizations are increasingly recognizing the need to use best training and development practices to enhance their competitive advantage over other corporate institutions.

Arguably, young personnel with entrepreneurial ambitions are aware that they lack experience and money; hence they try to join organizations which provide training programmes to prepare them for tomorrow's need (Feldman 2000). In so doing, development programme helps them to continue to be relevant and develop their abilities to cope with new technologies in the future. In agreement with this assertion, I-Cube, Information technology consulting firm in Massachusetts, according to Fenn (1999), offers I-Altitude, a development programme for their staff to enable them to easily adjust in the organization. Sustaining his contribution, Fenn (1999) states that training programme can lead to superior duties and higher remuneration for personnel. Besides, it helps staffs to improve their skills and knowledge in order to cope with the future requirements thereby guaranteeing them job satisfaction.

Basically, the image of an industry is hinged on the quality of training and development given to staff. As a result, organizations which are providing training and development programmes to their employees are getting success in retaining them. It is in this vein that Logan (2000) upholds that in localities where a manager provides assistance to their employees to develop professionally, turnover is almost 40-50 percentage fewer than those stores where association with the managers is not available. Sustaining this thought, Bartel (2000) avers that investment in training and development programme can be justified by the impact it creates in the development of personnel and organizational effectiveness. Thus, the importance of training and development programme for employees to advance their skills and competence in organizations cannot be overstressed as a lot of benefits accrue to them. New improved scientific skills as required by their job are learned.

Besides, the introduction of software and programmed systems is compelling personnel to appraise their expertise in order to remain resourceful in their employment. As a result, Feldman (2000) rightly observes that numerous employees have rehabilitated their attitude to acquire promotion inside their organizations to work and develop out of the organization. However, when personnel realize that organizations are lukewarm concerning them, they drop all sentiments about such organizations. Conversely, when organizations willingly invest in their workforce, they attract positive responses from them such they get value of their investments which, eventually benefits the organization (Wilson 2000). As a result, organizations providing training and development programmes for their personnel achieve high level of successes. This disclosure, according to Rosenwald (2000), increases organization's reliability for the reason that personnel recognize their organization is spending in their future career.

At this juncture, it is important to emphasize that loyalty with the organization cannot be calculated but it is substantial to intrinsic reward that personnel feel. As a result, they feel comfortable and want to stay with their organization, when they feel they are putting their efforts and skills in the bottom line for their organization 
(Logan 2000). It is this respect that Moses (2000) contends that personnel who are satisfied with their jobs, believe that their work has a purpose and important for their organization. Usually the best performing personnel do not leave a job for the purpose of financial benefits. Though salary and benefits play important roles in selecting and retention of the personnel, they are always observing, according to Wagner(2000), the opportunities to acquire novel skills, to get the encounter of different duties, and as well as looking for personal and professional development. During a qualitative study concerning mechanics in India, Barber (2004) says onthe-job training leads to superior novelty and implicit skills to perform jobs effectively.

While viewing training and development programme as basic to enhancing performance leading to the retention of qualified personnel in organizations, it is important to state that development refers to activities leading to the acquisition of new knowledge or skills for purposes of growing in organizations. For Manju and Suresh (2011), the technical skills of personnel serve as acts of intervention to improve organization's goods and services and to overcome stiff competition from rivals. Corroborating, Abdul Hameed (2011) citing an earlier position of Sheri-lynne(2007) affirms that organizations provide staffs with development programmes in order to enhance their capabilities thereby, making personnel development gaining an increasingly significant and strategic imperative in organizations. Writing earlier, Piper and Glatter (cited in Teather, 2002) view staff development as a systematic attempt to harmonize personnel interests and wishes, and their carefully assessed requirements for furthering their careers with the forthcoming requirements of the organization within which they are expected to work. "To retain staff, universities need to think seriously about their investment in training and development" (Leonard, 1998). For example, the normal monthly turnover at Unitel has decreased from 12 percent to 6 percent since they inaugurated Unitel University in 1998(Fenn, 1999). Though numerous persons involved with personnel training and development programmes are not assured of a direct association between the programmes and personnel retention (Rosenwald, 2000). However, specific numbers of university administrators discover that a constructive learning environment pointed to higher retention rates (Dillich 2000)

On the whole, the recognition accorded training programme by fresh university graduates is immense because it not only increases their salary (Dillich 2000), but enhances their skills and competence. Admittedly, it is also agreed that young personnel with entrepreneurial ambitions know that they have shortage of experience and money; hence they attempt to join organizations which provide training programmes to prepare them for the betterment of future (Feldman 2000). Personnel development programme help employees to survive in the future and develop their abilities to cope with new technologies. I-Cube, Information technology consulting firm in Massachusetts, provide employee development programme for their employees which is named by I-Altitude and offer to fresh employees so that they can easily adjust themselves in the organization (Fenn 1999). Continuing, Fenn (1999) say employees understand that training programme can directed to superior duties and higher remuneration. Furthermore, helping workers to improve their skills and knowledge to cope with the future requirements, lead to job satisfaction.

\subsection{Personnel training and development and improvement of academic collaboration}

The incidence of collaboration in academic research activities is increasing as a result of various factors. These factors include policy measures aimed at fostering partnership and networking among the various components of the research system, policies which are in turn justified by the idea that knowledge sharing could increase the effectiveness of the system. According to Martin-Sempere et al. (2002), researchers in the universities working as a team (unlike those who are not institution-based) show higher scientific productivity, higher propensity to international collaboration and to participation in international projects. It was further observed that establishing a research group is advantageous for the researchers: it makes contacts and collaborations easier, encourages participation in funded projects and increases the opportunities for publication in international journals.

Personnel development is fundamental to attaining increased output quality and advancing the image of universities through academic and scientific collaborations and this assertion remains undeniably true around the globe. Incontrovertibly, personnel development is globally seen as institutional policies, procedures, and practices deliberated upon to broaden the knowledge, skills, and attitudes of staff and, by so doing, improve the effectiveness an d efficiency of both of personnel and institutions(The Queens University of Belfast, 2006).Concurring to this, University of Western Australia (2006) says its Human Resource Policy (HRP) holds it as a word of honour to optimize opportunities for all staff to improve the levels of skills and knowledge of personnel thereby enhancing the quality of its productivity and satisfaction. What is more, the policy statement on staff development as articulated by University of Sussex (2006) lays emphasis on the development of its staff through encouraging an environment conducive to learning, and providing resources for learning in a variety of ways.

Over the last three decades, the scientific community has also stepped up activities to assess the actual impact of collaboration intensity on the performance of research systems. The use of collaboration has increased and gained in importance in the domain of scientific research over the last few decades. Various factors are responsible for this, including the growing specialization of science, the complexity of investigated problems and 
the increasing costs of scientific equipment needed to perform experiments. Other factors in favour of increasing collaboration cannot be ignored since results of painless access to public financing; aspirations for greater prestige and visibility were conclusions from collaboration with renowned research groups; and opportunities to attain higher productivity (Lee and Bozeman, 2005). European Union research policies have acknowledged and supported the creation of networks as essential tools for sharing knowledge and promoting innovation, towards the achievement of specific goals. These policies have included the overall Framework Programmes for research and development. In their different studies, Landry et al. (1996); Lee and Bozeman (2005) have demonstrated that academic and scientific collaborations contributed immensely to efficiency of organizations and as a result, national research policies have been focused on fostering more collaboration. In a more succinct way, it has been revealed those wide-ranging studies in the academic world and other studies, particularly international collaborations have produced genuine and outstanding results in the scientific performance of research groups (Van Raan, 1998; Martin-Sempere et al., 2002; Barjak and Robinson, 2007). Evidently, without training and development, all these collaborations would have yielded nothing. Sequel to this finding, since training and development have established improvement in academic and scientific collaborations thereby putting an end to obsolete academic thoughts in this 21 st century, the impact of collaboration has shown that researchers who are co-inventors of patents with private companies have a significantly higher scientific performance than their colleagues(Balconi and Laboranti, 2006). In addition, Lee and Bozeman (2005) have attempted to evaluate the degree to which collaboration among scientists influences scientific productivity, as measured in terms of publications. A sample of American university personnel (researchers) was surveyed and the results showed that the number of collaborating researchers is the strongest predictor of productivity and that the positive correlation between collaboration and productivity is adequately robust. It is in this desire to prove beyond all doubts that motivated Landry et al. (1996) to view academic and scientific collaborations involving university researchers in Quebec, and Canada. The data, collected through a survey and analyzed showed that collaboration intensity influences productivity to a varying degree with an econometric model. In a nutshell, collaborations generally contribute to scientific productivity, and therefore research policies should aim to foster collaborations. This has compelled staff in universities to form research teams, laboratories, or research centers, which are increasingly dominant over individual researchers in knowledge production (Wuchty et al., 2007). In essence, researchers have postulated that managing the flow of knowledge between networked communities can boost university performance, and by extension, improved the global image of such universities. In one example, Romano et al. (2014) concluded that management explained scientific outputs, measured in terms of patents, at an Italian university. It therefore behooves universities, as knowledge-based organizations, to manage their networks of collaboration. A management implementation has four phases: plan, organize, execute, and control. Control is a sub-process that contains: measure, evaluate, adjust, and return to plan. The following paragraphs describe how knowledge management was implemented at the university. Knowledge management was introduced to the University in this study in 2003 to intensify research collaboration, and thereby improve scientific performance. Designated research groups were central to the Knowledge Management Model. In the Model, the University provided seed money to a principal researcher to work with a group of faculty, postdoctoral researchers, and graduate students in a designated line of research.

\section{Methodology}

The study adopted survey research, and gathered data from questionnaires, interviews, observations, and other secondary sources such as textbooks, journals, and the Internet to understand how the impact of the poor implementation of organizational policies on personnel development has caused the dearth of qualified staff in Nigeria's universities. For Maduabum(2004), the survey design is directed towards determining the nature of situations as it exists at the time of the study. Similarly, Mugenda (1999) states that the survey design is the best method available to social scientists who are interested in collecting original data for the purposes of describing a population which is too large to observe directly. The total population of the study was two hundred and fifty(250) respondents selected purposively and the instrument for data collection was questionnaire. In essence, a total of 250 questionnaires were administered to respondents, and analyzed using the descriptive statistics and presented in percentages. On return, only two hundred and twenty $(220)$ questionnaires were retrieved and this represented 88\%. The structured questionnaire administered consisted of 15 questions, divided into 2 sections. Section A had three questions that focused mainly on the gender, age, and educational qualification of the respondents. The other 9 variables are relevant to the study because the study is basically targeted at understanding how poor implementation of organizational policies on personnel development has caused the dearth of qualified staff in Nigerian universities. The data was subjected to descriptive statistics, particularly percentage frequency table counts, which helped to strengthen the overall findings and conclusions of the study.

\section{Data presentation, Analysis and Discussion of findings}

This section deals with the presentation of the data from the study with reference to the objectives, and the 
responses from the research questions formulated to direct the study. In discussing the findings of this study, the research will focus attention on the analysis of the three research questions formulated and the presentation of the findings of the study through percentages since it was qualitatively analysed.

\subsection{Analysis of Research Questions}

From the analysis of the first research question, it was observed that is positive relationship between the impact of training and development on the competence of personnel in order to maximize productivity amongst repondents. To support this, 212 respondents representing 96.4\% agrees with the submission of Schuler and MacMillan(1984) that trainingand development of personnel is a contributing factor to the organizational effectiveness, while 8 respondents, a very insignificant number(3.6\%) counters training and development as a means to improving effeciency and productivity of personnel in organizations. To further ignore the minority report, it is upheld that the fundamental nature of training and development as an essential surviving component of every trade cannot be over emphasized as the value and potential of organizational personnel is recognized. This is because the quest for development triggers the acquisition of knowledge, and therefore the success of organizations. However, since the success of organizations is dependent on the knowledgeable, skilled as well as experienced personnel, most of organizations are nowadays, investing a lot of money on the training and development of personnel in order to remain competitive and successful. Besides, the importance of training and development of staff is rapidly growing and universities have become conscious about the optimum satisfaction and growth they have over their competitors. Therefore, investment in training and development programme can be justified by the impact it creates to develop staff and organizational effectiveness (Bartel, 2000). Thus, the importance of training and development programme for personnel to advance their skills and competence in organizations cannot be overstressed as a lot of benefits accrue to them. For example, new improved scientific skills are learned. In a similar way, many studies have highlighted different modes of training: in-service training, orientation programmes, refresher courses, conference presentation, research work, workshop attendance, and academic interaction, peer learning and even self development as essential for higher efficiency. In universities, research and innovation is an integral part of teaching/education.

Data gathered from the second research question showed that training and development can improve the retention of qualified personnel in the universities to confront unforeseen circumstances. Two hundred and six respondents(206) representing $93.6 \%$ are in agreement with the second research question, while ten(10) respondents $(4.6 \%)$ are in disagreement as they argue that the retention of personnel does not amount to the retention of personnel, but rather being loyal and committed to achieving the goals of organizations. At first thought, their position seem plausible, but at a second consideration, it withers away as the growth of organizations universally is measured by the productivity of personnel, and the productivity in question cannot be earned by being loyal and committed, but rather by embarking on training and development of personnel to transform organizations with the skills and knowledge acquired to accomplshing organizational goals. Concurring with this declaration, Logan(2000) posits that several organizations have revealed that one of the characteristics that help to keep personnel is to offer them opportunities to improve their learning. Corroborating this assertion, Garger (1999) affirms that companies are beginning to realize that experienced employees are important assets and organizations have to suffer the challenge for retaining them. Concurring, Moses (1999) holds that organizations are beginning to plan for future through implementing policies on training and developing their new personnel for exalted positions in future. This commitment, obviously, can be explained as emotional accord by which employers are usually assured loyalty for long term dedication, and on the other hand, providing employees work safety, chances for advancement in career, and training opportunities (Feldman 2000). Sequel to this, high performing organizations are increasingly recognizing the need to use best training and development practices to enhance their competitive advantage over other corporate institutions. By implication, personnel have become valued resources to the extent that the success or failure of organizations speaks volumes about the quality of training and development programmes given to personnel.

From the third research question, two hundred and six respondents( $90.9 \%)$ admit that there is a positive relationship between training and development and improvement through academic and scientific collaborations thereby putting an end to obsolete academic thoughts in this century, while twelve respondents(5.5\%) do not believe in academic and scientific collaborations to attain productivity. On the other hand, eight respondents(3.6\%) are undecided in their position. However, in their different studies, Landry et al. (1996); Lee and Bozeman (2005)demonstrated that academic and scientific collaborations contribute immensely to efficiency of organizations and as a result, national research policies have been focused on fostering more collaboration. Similarly, the degree to which collaboration among personnel (scientists) influences productivity, as measured in terms of publications has been evaluated and acknowledged by Lee and Bozeman (2005).

Basically, the assessment of research productivity has gained increasing importance among scholars and research policy-makers for years now. A study by Ramsden (1994) looked into the Australian university system. Its results broadly confirmed Fox's $(1983,1992 \mathrm{a}, 1992 \mathrm{~b})$ conclusions that high levels of scientific productivity 
result from the combination of personal and environmental factors. The results showed that the number of collaborating researchers is the strongest predictor of productivity and that the positive correlation between collaboration and productivity is adequately robust. Concisely, if the single determinants of productivity are considered, scientific collaboration is among those unanimously recognized as exerting a significant influence on the performance of individual researchers and institutions, in terms of both effectiveness and efficiency. So much so that it has become a cornerstone in research policies at national and supranational level.

In essence, researchers have postulated that managing the flow of knowledge between networked communities can boost university performance, and by extension, improved the global image of such universities. In one example, Romano et al. (2014) concluded that management explained scientific outputs, measured in terms of patents, at an Italian university. It therefore behooves universities, as knowledge-based organizations, to manage their networks of collaboration.

\section{Conclusion}

The findings of this study show that training and development ultimately upgrades not only the productivity of personnel, but also of tertiary institutions. Since personnel are highly esteemed resource of organization, it has rightly been said that with adequate manpower development in organizational structure designed with a clear mission and vision, and well-articulated policy, and strategic plan, the performance of personnel in achieving organizational set goals is assured, and will in the long run become the key to university sustainable development. However, it is important that tertiary institutions must have personnel that can quickly adapt to an ever-changing academic and scientific world. During the recruitment of personnel, meritocracy must supersede all other considerations to ensure that trainable personnel are employed. Through this, tertiary institution can invest in the training and development of personnel to add value in their jobs, gaining competitive advantage and seeking self growth beyond COVID-19.

Implicitly speaking, the 21 st century will be approving to those tertiary institutions, which are able to train and develop their personnel to learn faster and adapt to new changes than their competitors. In as much as job satisfaction is important, every organization must begin to train and develop personnel who are capable of swiftly adjusting to a continuously fluctuating business environment beyond COVID -19 to justify the huge investment in them.

\section{Recommendations}

Based on the findings, and conclusion, the following recommendations are hereby provided:

(i) First, since training enhances personnel initiative and quality of vocation, and also assist them to be more committed to achieving universities' set goals and objectives and which in turn, enhances staffs' effectiveness within the university, it is most recommended that whilst the rest of the world is coming to terms with the dramatically changing landscape of universities as centers of knowledge generation, dissemination, and consumption, Nigeria should act timely and wisely by embracing the tenets of training and development of personnel for higher productivity.

(ii) Besides, one of the reasons for personnel being preferred dominantly to spend their time on professional development activities is in order to improve their teaching skills and increasing subject knowledge. Sequel to this, the study recommends that the various training and development programmes should result from the need for institutional development plan and priorities, than individuals' lecturers' needs and interest. As a result, personnel involvement in planning and enacting the professional development initiatives should either less regarded or totally neglected because it has been seen that the present system of personnel development practice has little or no contribution to the promotional prospects and career development perspectives.

(iii) In addition, the existing system of training and staff development is a top-down approach, which is dominantly characterized by donor driven than demand driven. Thus, the place of personnel developing, and fully participating in the preparation of materials and institutionalization of the professional development programme, is totally nonexistent. Thus, the existing system of staff development that has been a top down approach, should be reversed to down-top approach

(iv) Things, events, thought are changing at faster rate; therefore to deal with such dynamic situation, the need to change our acquiring education is imperative. Since there are institutions sufficiently equipped with professional knowledge, trainings and developments of personnel to achieve set objectives, they are necessary and indeed very valuable. In actual fact, it is believed that one way to augment the competencies of personnel is through provision of professional development training. Thus the usefulness of professional development activities to improve personnel expertise should be painstaking.

(v) As one component of the professional development training, trainees are expected to carry on action research at least in group. This study suggests that when action research is carried out in group it 
will have some value, especially in developing team spirit, to solve problem collaboratively. As a whole, this study believes that action research can bring change on the level of personnel competencies and the environment of teaching and learning in general.

(vi) Finally, since personnel training and development programmes have become a foreseeable strategy to increase output, organizations should have it in-built in their system in order to survive in the current changing demands of Covid 19. In other words, since personnel development is a vital element to the survival and growth of organizations, all hands must be on deck to carefully plan and implement training and development programmes to survive these trying times.

\section{REFERENCES}

Abdul Hameed Aamer Waheed (2011). "Employee Development and Its Affect on Employee Performance: A Conceptual Framework". International Journal of Business and Social Science Vol. 2 No. 13 [Special IssueJuly], 224

Adama University (2012). Education Research International Volume 2012,doi:10.1155/2012/624241

Alliger GM, Tannenbaum SI, Bennett W Jr, Traver H, Shotland A. (1997). A meta-analysis of the relations among training criteria. Journal of Personal Psychology, 50:341-58.

Ana Paula Vieira Gomes Ferreira(2016) Training and Developmenti n Organizations: Start at the Beginning. Springer International Publishing Switzerland

Anyamele, S. C.(2004).Institutional management in higher education: a study of leadership approaches to quality improvement in university management. Nigerian and Finnish cases [Ph.D. dissertation], Department of Education, University of Helsinki

Balconi M., Laboranti A., (2006).University-industry interactions in applied research: The case of microelectronics Research Policy, 35, 1616-1630.

Barber J. (2004). Skill upgrading within informal training: lessons from the Indian auto mechanic. International Journal of Training and Development, 8:128-39.

Bartel, A.P. (2000). Measuring the Employer's Return on Investment in Training: Evidence from the Literature. Industrial Relations, 39, 3, 502-524.

Bartlett, K.R. (2001). The Relationship between Training and Organizational Commitment: A Study in the Health Care Field. Human Resource Development Quarterly, 12, 4, 335-352.

Barjak F., Robinson S. (2007). International collaboration, mobility and team diversity in the life sciences: impact: on research performance, Social Geography Discussion, 3, 121-157.

Belkhodja O., Landry R., (2005). The Triple Helix collaboration: Why do researchers collaborate with industry and the government? What are the factors influencing the perceived barriers? 5th Triple Helix Conference, Turin, Italy, May 18th-21st 2005.

Bordons M., Gómez I., Fernández M. T., Zulueta M. A. Méndez A.,(1996). Local, Domestic and International Scientific Collaboration in Biomedical Research, Scientometrics, 37, 2, 279-295.

Chaminade B (2007). A retention checklist: how do you rate?Www.humanresourcesmagazine.co.au.

Colarelli, S. M., and Montei, M. S. 1996. Some contextual influences on training utilization. The Journal of Applied Behavioral Science, 32(3): 306-322.

Cuniff, J. (2000, July 26). Lifelong education has become the norm. Milwaukee Journal Sentinel, 35Q. Sage, Thousand Oaks, Calif,USA, 2nd edition.

Desta, M (2004. ) "Observations and reflection of the Higher Education Teachers on quality of Teaching and Learning in Higher Education in Ethiopia," The Ethiopian Journal of Higher Education , vol. 1, No. 1

Dillich, S. (2000, August 4). Corporate universities. Computing Canada, 26 (16), 25.

Dolezalek, H. (2005). 2005 Industry report. Training, 42(12), 14"28

Duke, C (1992). The Learning University: Towards a New Paradigm. Buckingham and Bristol: The Society for Research into Higher Education, Open University Press

Dukhan, N. R., N. Mohamad, and A. B. Ali( 2017). Factors affecting on the employees' performance study on the Al-Zawiya University of Libya. International Review of Management and Business Research 6 (1): 145.

Ekaterini Galanou, Constantinos-Vasilios Priporas (2009): "A model for evaluating the effectiveness of middlemanagers"e training courses: evidence from a major banking organization in Greece". International Journal of raining and Development, pp 221-245.

Feldman, D. (2000, May). The Dilbert syndrome: How employee cynicism about ineffective management is changing the nature of careers in organizations. American Behavioral Scientist, 43, 1286-1301.

Fenn, D. (1999, February). Corporate universities for small companies. Inc, 21 (2), 95-96.

Fullan, M. G. (2001). The New Meaning of Educational Change, Teachers College Press, New York, NY, USA, 2nd edition

Gambone, A; Klem, M and Connell, J.P (2002). Finding out What Matters for Youth: Testing Key Links in a Community Action Framework for Youth Development. Philadelphia: Youth Development Strategies and 
Institute for Research and Reform in Education, http://www.ydsi.org/ YDSI/pdf/ WhatMatters.pdf

Garger, E. M. (1999, November). Goodbye training, hello learning. Workforce, 78 (11), 35-42.

Garrow, V. (2004). Training and Development and the Psychological Contract. Training Journal, April 8-10.

Gerbman, R. V. (2000, February). Corporate Universities 101. HR Magazine, 45 (2), 101-106.

Giovanni Abramo, Ciriaco Andrea D'Angelo, Flavia Di Costa(2008) Research collaboration and productivity: is there correlation? Higher Education· February 2008 DOI: 10.1007/s10734-008-9139-

Goldstein IL, Ford JK. (2002). Training in Organizations. Belmont, CA: Wadsworth. 4th ed.

Graham, K. \& Tierney, J. (2003). Improving teacher education through human resource development at ITEK. Midterm review for Nuffield Foundation

Haigh, N. (1998). Staff development: an enabling role. In Latchem \& Lockwood (1998) pp. 182-192.

Héctor G. Ceballos, James Fangmeyer Jr., Nathalíe Galeano, Erika Juarez \& Francisco J. Cantu-Ortiz(2017). Impelling research productivity and impact through collaboration: a scientometric case study of knowledge management, Knowledge Management Research \& Practice, 15:3, 346-355, DOI: 10.1057/s41275-0170064-8

James K. Jackson, et al (2020) Global Economic Effects of COVID-19.Congressional Research Service https://crsreports.congress.gov R46270

Jelena Vemic (2007): "Employee Training and Development and The Learning Organization". Facta Universitatis Series; Economics and Organization Vol. 4, No 2, 2007, Pp. 209 -216.

Kate Hutchings, Cherrie J. Zhu, Brain K, Cooper, Yiming Zhang and Sijun Shao (2009):"Perceptions of the effectiveness of training and development of "grey-collar"e workers in the People's Republic of China". Human Resource Development International, Vol.12, No.3, pp 279-296.

Katz, J., and Martin, B.R. (1997). What is research collaboration? Research Policy 26 (1): 1-18.

Khawaja \& Nadeem (2013): "Training and Development Program and its Benefits to Employee and Malaysia: Organization: A Conceptual Study". European Journal of Business and Management. Vol.5, No.2

Kim, Y., Horta, H. and Jung, J (2017). Higher education research in Hong Kong, Japan, China, and Exploring research community cohesion and the integration of thematic approaches. Studies in Higher Education 42: 149-168.

Konings, Jozef \& Vanormelingen, Stijn. (2009). “The Impact of training on Productivity and Wages: Firm Level Evidence". Discussion paper No. 244, Available at SSRN.

Kraiger, K(2003). Perspectives on training and development. Handbook of Psychology

Lancho Barrantes, B.S., V.P. Guerrero Bote, Z. Chinchilla Rodriguez,and Anegon F. de Moya(2012). Citation flows in the zones of influence of scientific collaborations. Journal of the American Society for Information Science and Technology 63 (3): 481-489.

Lepak, D., and M. Gowan(2010). Human Resource Management. Managing Employees for Competitive Advantage. New Jersey NJ: Pearson-Prentice Hall.

Lee, S., and B. Bozeman. 2005. The impact of research collaboration on scientific productivity. Social Studies of Science 35 (5): 673-702.

Logan, J. K. (2000, April). Retention tangibles and intangibles: More meaning in work is essential, but good chair massages won't hurt. Training and Development, 54 (4), 48-50.

Lowry, D.S., A. Simon and N. Kimberley. 2002. "Toward improved employment relations practices of casual employees in the New South Wales registered clubs industry". Human Resource Development Quarterly, Vol.13, No1, pp 53-69.

Loucks-Horsley, S. Hewson, P. W. Love, N. \& Stiles, K. E.(1998) Designing Professional Development for Teachers of Science and Mathematics, Corwin Press, California, Calif, USA.

Maimuna Muhammad Nda \& Rashad Yazdani Fard(2013). The impact of employee training and development on employee productivity. Global .Journal of .Commerce and Management Perspective;Vol.2 (6): :91-93 (November-December

Nishtha Langer and Amit Mehra (2010), "How Training Jump-Starts Employee Performance", Indian Management, Vol 49(6), pp: 14-18.

Nunn, J. (2000, September/October). Career planning key to employee retention. Journal of Property Management, 65 (5), 20-21.

Mel Kleiman (2000, January). What happens if you don't train them and they stay? Occupational Health and Safety, 69 (1), pp. 18, 70.

Moses, B. (1999, February 1). Career planning mirrors social change. The Globe and Mail [On-Line]. Retrieved from the World Wide Web: http://www.bbmcareerdev.com/careerplan.html

O'Herron, P., and Simonsen, P. (1995, May). Career development gets a charge at Sears Credit. Personnel Journal, 74 (5), 103-106.

Onuocha, I. and Ewuzie, K. (2012) "Employers Worry as Nigerian Degrees Face Quality Test”, in Business Day, September 14th. 
Paradise A. (2007): State of the Industry: ASTD's Annual Review of Trends in Workplace Learning and Performance. Alexandria, VA: ASTD

Rohan, S. \& Madhumita, M. (2012).“ Impact of Training Practices on Employee Productivity: A comparative study" Inter science Management Review. Volume-2, Issue-2

Romano, M., M. Del Giudice, and M. Nicotra(2014). Knowledge creation and exploitation in Italian universities: The role of internal policies for patent activity.Journal of Knowledge Management 18 (5): 952-970.

Rosenwald, M. (2000, October 15). Working class: More companies are creating corporate universities to help employees sharpen skills and learn new ones. Boston Globe, H1.

Salas, E., and J. A. Cannon-Bowers. 2001. The science of training: A decade of progress. Annual Review of Psychology 52 (1): 471-499.

Satterfield JM, Hughes E. (2007):'Emotion skills training for medical students: a systematic review”. Medical Education 41:935-41.

Schmidt Steven W (2009), "Employee demographics and job training satisfaction: the relationship between dimensions of diversity and satisfaction with job training", Human Resource Development International, vol.12, No.3, pp 297-312

Schuler, R.S., and MacMillan, I.C. (1984). Gaining Competitive Advantage through Human Resource Management Practices. Human Resource Management, 23, 3, 241-255.

Sepulveda, Facundo. (2005): “Training and Productivity: Evidence for US Manufacturing Industries” Available at SSRN

Sheeba Hamid (2011): “A Study of Effectiveness of Training and Development Programmes of UPSTDC, India-An analysis", South Asian Journal of Tourism and Heritage, Vol.4 (1)

Seligson, M and P. Stahl, P(2003) Bringing Yourself to Work: A Guide to Successful Staff Development in after-School Programs, Teachers College Press, New York, NY, USA.

Settoon, R.P., Bennett, N., and Liden, R.C. (1996).Social exchange in organizations: Perceived organizational support, leader-member exchange, and employee reciprocity. Journal of Applied Psychology, 81, $219-227$.

Teather, D. C (2002). Staff Development in Higher Education, Kogan Page, New York, NY, USA

Temesgen, M.(2006) Design and development of online professional development program for teacher educators in Bahir Dar University [M.S. thesis], University of Twente, Enschede, TheNetherlands.

Seyoum, Yilfashewa (2012). Staff Development as an Imperative Avenue in Ensuring Quality:The Experience of Adama University. Education Research International Volume 2012, doi:10.1155/2012/624241

The Queens University of Belfast, Policy Statement, University of Cambridge, Staff Development Policies, 2006,http://www.admin.cam.ac.uk/offices/personnel/staffdev/.

University of Cambridge (2006). "Staff Development Policies," http://www.admin.cam. .ac.uk/ offices/personnel/staffdev//.

University of Western Australia(2006)."Staff Development," http:/www.hr.nwa.edu. ac/policy/ toc/ appointment \&emplo-staff develomentyment/.

University of Sussex(2006). "Staff Development," http://www.Sussex.ac. .uk/units/staffing/ staffdev/ policies/staffdev.html.

Vinesh (2014). Role of Training \& Development in an Organizational Development. International Journal of Management and International Business Studies.Vol.4, No. 2 pp. 213-220

Walker, G., Kogut, B \& Shan,W(1997). Social capital, structural holes and the formation of an industry network. Organization Science 8 (2): 109-125.

Wenger, E., \& Snyder,W(2000). Communities of practice: The organizational frontier. Harvard Business Review.78: 139-145.

Wuchty, S., Jones, B \& Uzzi, B(2007).The increasing dominance of teams in production of knowledge Science 316 (5827):1036-1039. 